\title{
Propriedade Intelectual: proteção e gestão estratégica do conhecimento
}

\section{Elza Fernandes Araújoํㅜㄹ Cynthia Mendonça Barbosa², Elaine dos Santos Queiroga ${ }^{3}$, Flávia Ferreira Alves ${ }^{4}$}

${ }^{1}$ Departamento de Microbiologia da Universidade Federal de Viçosa - PQ/CNPq. Presidente da Comissão Permanente de Propriedade Intelectual CPPI/UFV e Coordenadora da Rede Mineira de Propriedade Intelectual - RMPI.

2 Graduanda em Ciências Contábeis, Bacharel em Administração de Empresas e Pós-Graduanda em Gestão Estratégica todos pela Universidade Federal Viçosa. Bolsista BGCT/FAPEMIG pela Rede Mineira de Propriedade Intelectual.

${ }^{3}$ Graduada em Direito pela Universidade Federal de Viçosa e bolsista BGCT/FAPEMIG pela Comissão Permanente de Propriedade Intelectual CPPI/UFV.

${ }^{4}$ Mestre em Ciência e Tecnologia de Alimentos pela Universidade Federal de Viçosa. Bolsista BGCT/FAPEMIG pela Comissão Permanente de Propriedade Intelectual CPPI/UFV.

RESUMO - Além de garantir o direito de propriedade e exclusividade ao titular da criação intelectual, a proteção da propriedade intelectual permite o avanço da inovação e a divulgação dos conhecimentos, equilibrando os interesses do titular e acarretando benefícios para a sociedade. Neste sentido, a Propriedade Intelectual é estratégica no cenário globalizado e competitivo, no qual o conhecimento e a capacidade de inovar têm papel importante para o desenvolvimento de um país. Assim, visando à gestão da propriedade intelectual, com foco na inovação, faz-se necessário incentivar a cooperação entre a ICT e a empresa, para a realização de pesquisas e desenvolvimento tecnológico conjuntos, bem como dinamizar os processos de licenciamento e transferência de tecnologia. Nesse sentido, as ICTs com o auxílio dos NITs devem adotar políticas de gestão da Propriedade Intelectual, elaborando instrumentos jurídicos adequando o ambiente acadêmico ao contexto regulatório. Cabe às ICTs, por meio do NITs, estimularem a cultura da proteção da propriedade intelectual gerada na Instituição, podendo as mesmas atuarem em rede, aprimorando e avançando na gestão da propriedade intelectual. A Propriedade Intelectual é um fator estratégico para a inovação científica e tecnológica e, no Brasil, tem-se buscado a convergência dos setores público e empresarial, com o propósito de contribuir para o desenvolvimento científico, tecnológico e social do país, por meio de um processo contínuo com ações conjuntas e coordenadas.

Palavras-chave: gestão em rede, inovação científica e tecnológica, instituições científicas e tecnológicas, núcleo de inovação tecnológica, Propriedade Intelectual

\section{Intellectual Property: protection and management of knowledge}

ABSTRACT - Besides ensuring property and exclusive rights to holders of intellectual creation, intellectual property protection allows innovation and spread of knowledge, balancing the interests of the holder and the benefits to society. In this sense, Intellectual Property is strategic in the globalized and competitive world scenario, in which knowledge and innovation capacity play an important role in the development of a country. Therefore, aiming at intellectual property management with focus on innovation, it is necessary to encourage cooperation between the ICT and companies, for the accomplishment of conjoint research works and technology development, besides boosting licensing procedures and technology transfer. Therefore, ICTs, with the help of NITs, should adopt policies for managing intellectual property, creating legal instruments and adapting the academic environment to the current regulations. The ICTs are responsible for stimulating the protection of intellectual property generated in the institution, by means of the NITs. They may operate in a network, improving and advancing the management of intellectual property. Intellectual property is a strategic factor for scientific and technological innovation. In Brazil, the collaboration between public and business sectors has been sought, aiming at the scientific, technological and social development of the country, through a continuous process of conjoint and coordinated actions.

Key Words: center for technological innovation, Intellectual Property, network management, scientific and technological innovation, scientific and technological institutions 


\section{Introdução}

\section{A Propriedade Intelectual}

Propriedade intelectual pode ser compreendida como o direito de pessoa, física ou jurídica, sobre um bem incorpóreo móvel (Di Blasi, 2005). Assim, a propriedade intelectual corresponde ao direito sobre criações intelectuais, por determinado período de tempo, estabelecido de acordo com os preceitos legais. Esse direito exclusivo, advindo da propriedade intelectual, abrange as criações artísticas, literárias, tecnológicas e científicas.

Analisando a origem da proteção do conhecimento, encontramos os primeiros relatos de proteção na segunda metade do século $\mathrm{XV}$, cuja propriedade intelectual relacionava-se a autores de obras literárias. A proteção era concedida pelos reis e senhores feudais e os critérios de proteção eram os mais diversificados, dependendo muitas vezes da simpatia do soberano (Di Blasi, 2005). No Brasil, há evidências de que a primeira outorga de privilégios foi para uma máquina de descascar arroz, concedida em 1752, por um prazo de 10 anos (Di Blasi, 2005).

Conforme a Organização Mundial da Propriedade Intelectual (OMPI), a propriedade intelectual corresponde à soma dos direitos relativos às obras literárias, artísticas e científicas, às interpretações dos artistas intérpretes e às execuções dos artistas instrumentistas, aos fonogramas e às emissões de radiodifusão, às invenções em todos os domínios da atividade humana, às descobertas científicas, aos desenhos e modelos industriais, às marcas industriais, comerciais e de serviço, bem como às firmas comerciais e denominações comerciais, à proteção contra a concorrência desleal e todos os outros direitos inerentes à atividade intelectual nos domínios industrial, científico, literário e artístico.

Nesse sentido, a propriedade intelectual confere ao autor, inventor e/ou titular do conhecimento protegido o poder sobre as criações. O poder concedido permite aos mesmos executarem procedimentos com intuito de resguardarem os seus direitos, como: proibir terceiros, sem o seu consentimento, de produzir, utilizar, vender ou importar a sua invenção, modelo de utilidade ou desenho industrial; impedir que terceiros reproduzam ou imitem a sua marca; tomar medidas contra aqueles que estejam fabricando, importando, exportando, vendendo, expondo, oferecendo à venda ou mantendo em estoque produto que apresente falsa indicação geográfica; entre outros.
Além de garantir o direito de propriedade e exclusividade ao titular da criação intelectual, proporcionando-o os meios de defesa contra apropriação indevida do seu conhecimento por parte de terceiros e o privilégio da exclusividade na exploração da criação, a proteção da propriedade intelectual permite que uma nação promova a inovação e a divulgação dos conhecimentos, equilibrando os interesses do inventor, autor e/ou titular e as necessidades gerais da sociedade.

Essa preocupação por parte dos países em aliar os interesses do proprietário de uma criação intelectual aos interesses da sociedade é evidenciada pela OMPI e remonta tempos atrás, conforme mencionado por Di Blasi (2005), o qual relata que, desde os primeiros textos de cartas de privilégio concedidas, existia a preocupação dos governos em proteger os direitos não somente dos autores, inventores e/ou titulares, mas também fomentar o progresso científico e tecnológico.

Em entrevista realizada com o doutor em Economia, Marc Giget (Revista IEL Interação, 2010), o mesmo também ressalta a importância da ligação entre o que ele denomina de mundo do conhecimento, tecnologias e Know-how, que representa o mundo da propriedade intelectual, e o mundo da sociedade, para o qual o conhecimento, a tecnologia e o know-how se destinam, para promover a inovação.

Segundo Giget (2010), inovação consiste na combinação de conhecimentos, habilidades, talentos, que exigem a reunião de equipes que partilham projetos comuns. Sob a visão de Giget, a inovação representa, para o setor empresarial, menos gastos e maior satisfação de seus clientes e, para a sociedade, um progresso real, uma vez que, por meio da inovação, há introdução de novidade ou aperfeiçoamento no ambiente produtivo ou social, resultando em novos produtos, processos ou serviços, levando-se em consideração o estabelecido no Art. $2^{\circ}$, inciso IV, do Decreto n ${ }^{\circ} 5.563$, de 11 de outubro de $2005^{1}$.

Assim, a propriedade intelectual consiste em fator estratégico para a inovação tecnológica. Segundo Paulo A. Ferreira (Revista IEL Interação, 2010), diretor-geral do IEL Nacional e presidente da Federação das Indústrias do Estado de Goiás, a propriedade intelectual é um instrumento fundamental no cenário globalizado e competitivo, no qual o conhecimento e a capacidade de inovar têm papel importante, consistindo em um diferencial de competitividade.

Neste contexto da geração, proteção e gestão do conhecimento em prol da inovação, visando ao desenvolvimento científico, tecnológico, econômico e social

\footnotetext{
1 Art. $2^{\circ}$ - Para os efeitos deste Decreto, considera-se: (...)

IV - Inovação: introdução de novidade ou aperfeiçoamento no ambiente produtivo ou social que resulte em novos produtos, processos ou serviços.
} 
de um país, estão inseridas as Instituições Científicas e Tecnológicas - ICTs. Estas, conforme estabelecido no Art. $2^{\circ}$, inciso V, do Decreto ${ }^{\circ} 5.563$, de 11 de outubro de $2005^{2}$, consistem em órgãos ou entidades da administração pública que apresentam como missão institucional, dentre outras, executar atividades de pesquisa básica ou aplicada de caráter científico ou tecnológico.

Analisando a atuação das ICTs e a gestão no âmbito da propriedade intelectual, é possível verificar que os conhecimentos gerados nessas instituições se transformam em inovação à medida que são disponibilizados à sociedade, por meio de parcerias entre as ICTs e o setor empresarial.

Neste caso, visando a gestão da propriedade intelectual, com foco na inovação, faz-se necessário incentivar a cooperação entre a ICT e as empresas e dinamizar os processos de licenciamento e transferência de tecnologia, como também as interações para realização de pesquisas conjuntas. Se os conhecimentos gerados nas ICTs não são licenciados ou transferidos, a inovação científica e tecnológica não ocorre, como também os benefícios econômicos e sociais almejados com a propriedade intelectual.

\section{A Propriedade Intelectual no Brasil}

A Propriedade Intelectual no Brasil está dividida em três modalidades: Direito Autoral, Proteção Sui generis e Propriedade Industrial (Figura 1).

O Direito Autoral é subdividido em Direitos de Autor, Direitos Conexos e Programas de Computador. De acordo com a Lei ${ }^{\circ}$ 9.610, de 19 de Fevereiro de 1998, os Direitos Autorais são aqueles ligados ao autor como consequência de obra por ele elaborada. Na Lei supracitada, somente as criações de espírito, expressas por qualquer meio ou fixadas em qualquer suporte conhecido ou que se invente no futuro, são obras intelectuais passíveis de proteção. No Brasil, a Fundação Biblioteca Nacional é a responsável por registrar as obras intelectuais originárias do país. Vale ressaltar que a partir do momento que o autor registra sua obra, ele adquire vários benefícios, entre eles: comprovação da sua autoria perante terceiros; especificação de seus direitos morais e patrimoniais e contribuição para preservação da memória nacional. Porém não são os autores os únicos contribuintes para a criação intelectual, há casos em que algumas obras não chegam ao público senão por meio de intermediários, que tornam a obra perceptível.

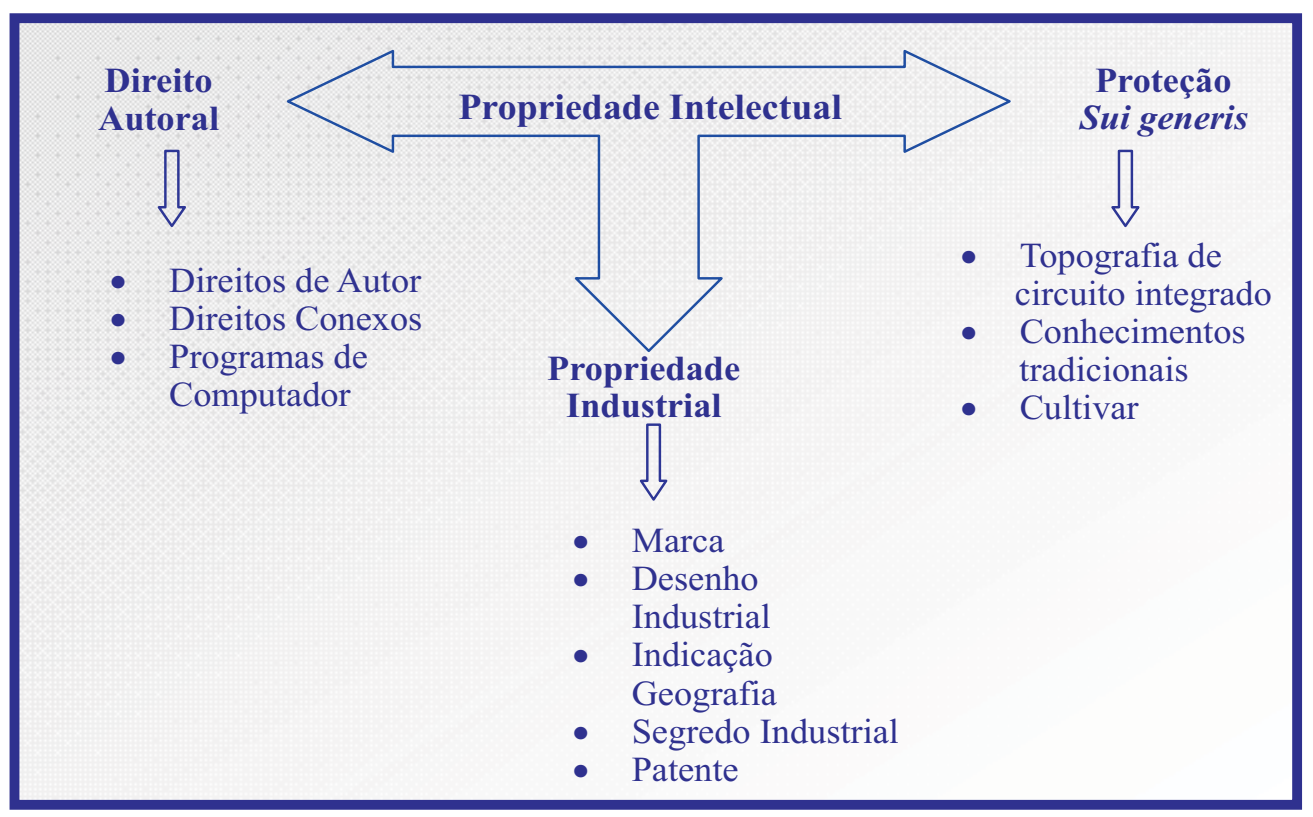

Figura 1 - Modalidades da Proteção Intelectual no Brasil.

\footnotetext{
${ }^{2} \mathrm{~V}$ - Instituição Científica e Tecnológica - ICT: órgão ou entidade da administração pública que tenha por missão institucional, dentre outras, executar atividades de pesquisa básica ou aplicada de caráter científico ou tecnológico.
} 
Considerando este fato, o objetivo dos Direitos Conexos é proteger os interesses jurídicos destas pessoas que contribuem para tornar as obras acessíveis ao público. Como exemplo dos possuidores destes direitos, pode ser citado cantores que interpretam músicas não compostas por eles (OMPI, 2010). A Lei n 9.610/1998 estabelece as normas pertinentes aos Direitos de Autor como também aos Direitos Conexos. Os direitos de autor e conexos são válidos por 70 anos, a contar a partir de $1^{\circ}$ de janeiro do ano subsequente à fixação da obra.

De acordo com a Organização Mundial de Propriedade Intelectual-OMPI, Programa de Computador se refere a um conjunto de instruções que controla as operações de um computador para permitir que ele execute uma tarefa específica, como a armazenagem e a recuperação de informações. O regime de proteção de um Programa de Computador é o mesmo dado às obras literárias pela legislação de Direitos Autorais, sendo facultado ao inventor do programa registrar a sua criação e, ainda, é a Lei n 9.609, de 19 de Fevereiro de 1998, que disciplina este tema. Diferentemente das outras submodalidades do Direito Autoral, o registro do Programa não é realizado junto à Fundação Biblioteca Nacional, e sim no Instituto Nacional da Propriedade Industrial - INPI. A validade dos direitos, para quem desenvolve um Programa de Computador, é de 50 anos, contados a partir de $1^{\circ}$ de janeiro do ano subsequente ao da sua data de criação.

Na modalidade de Proteção Sui generis estão incluídos Topografia de Circuito Integrado, Conhecimentos Tradicionais e Cultivares. Conforme o INPI, Circuito Integrado - CI se refere a um conjunto organizado de interconexões, transistores e resistências, dispostos em camadas sobre ou no interior de uma peça e que tem por objetivo a realização de funções eletrônicas. A Topografia de CI consiste em uma série de imagens relacionadas, construídas ou codificadas sob qualquer meio ou forma, que represente a configuração tridimensional das camadas que compõem um CI (ADENACON, 2010). Alguns CI são utilizados como memória dos tipos RAMs, ROMs e EPROMs, enquanto outros são processadores realizando funções lógicas e matemáticas em computadores (Barbosa, 2007). Em 2007, foi aprovada no Brasil a Lei $n^{\circ} 11.484$, de 31 de Maio de 2007, para a proteção das Topografias como um direito de propriedade intelectual. O criador/inventor da Topografia para ter esse direito precisa registrá-la junto ao INPI, sendo que a proteção é valida por 10 anos a contar da data do registro.

Conhecimento Tradicional - CT significa o conhecimento que resulta da atividade intelectual em um contexto tradicional e que inclui Know how, habilidades, inovações, aprendizados, práticas e conhecimento usado no estilo de vida tradicional de uma comunidade ou povo e que seja transmitido de geração em geração. Como exemplo dos possuidores deste tipo de proteção pode ser citado os povos indígenas que há séculos vêm utilizando plantas nativas com propósitos terapêuticos. O CT pode ser protegido por praticamente todas as modalidades de Direito de Propriedade Intelectual, porém deverá preencher os critérios de cada tipo de proteção.

Outra submodalidade da Proteção Sui generis são as cultivares. Cultivar pode ser definida como uma subdivisão de uma espécie agrícola que se distingue de outra por qualquer característica perfeitamente identificável, seja de ordem morfológica, fisiológica, bioquímica ou outras julgadas suficientes para sua identificação (MAPA, 2010). Em outras palavras, cultivar é uma nova variedade de espécie vegetal geneticamente melhorada. No caso de cultivares, para sua comercialização é necessário registrálas junto ao Registro Nacional de Cultivares (RNC). Entretanto, para a pessoa física ou jurídica que obtém as cultivares cobrar e receber royalties do licenciamento, as cultivares deverão estar protegidas no Serviço Nacional de Proteção de Cultivares (SNPC/MAPA). Sendo assim, o registro não implica em proteção. Ressalta-se que tanto a proteção quanto o registro são realizados junto ao Ministério da Agricultura Pecuária e Abastecimento - MAPA. No Brasil, a Lei n 9.456, de 25 de Abril de 1997, disciplina a proteção de cultivares, sendo o prazo de proteção de 15 anos para a maioria das espécies e de 18 anos para as videiras e árvores frutíferas, florestais e ornamentais (MAPA, 2010).

A última modalidade de Propriedade Intelectual que iremos tratar neste artigo se trata da Propriedade Industrial. Neste tipo de proteção estão incluídos Marca, Desenho Industrial, Segredo Industrial, Indicação Geográfica e Patente. A Lei $n^{\circ}$ 9.279, de 14 de maio de 1996, Lei da Propriedade Industrial-LPI, disciplina as questões relativas à propriedade industrial no Brasil, e a proteção das submodalidades, exceto o caso do Segredo Industrial, deve ser requerida junto ao INPI.

Marca pode ser definida como todo sinal visualmente perceptível, usado para distinguir um produto ou um serviço de outro, semelhante ou igual, bem como pode ser o sinal usado para identificar produtos ou serviços originados de membros de uma determinada entidade, marca coletiva, ou sinal que sirva para atestar a conformidade de um produto ou serviço com certas normas ou especificações técnicas, marca de certificação (INPI, 2010). A proteção da marca é 
válida por 10 anos, contados da data de concessão do registro, e poderá ser prorrogada inúmeras vezes, a critério do proprietário da marca

Segundo a LPI, Desenho Industrial consiste na forma plástica ornamental de um objeto ou o conjunto ornamental de linhas e cores que possa ser aplicado a um produto, proporcionando resultado visual novo e original na sua configuração externa e que possa servir de tipo de fabricação industrial. A proteção vigorará pelo prazo de 10 anos, contados da data de depósito, podendo ser prorrogável por três períodos sucessivos de cinco anos cada.

Segredo Industrial pode ser definido como um conjunto de informações, incorporadas ou não a um suporte físico, que por não ser acessível a determinados concorrentes representa vantagem competitiva para os que o possuem e o usam (Barbosa, 2002). Os segredos industriais são protegidos sem registro, isto é, não existe decisão sobre a concessão da proteção. Um segredo industrial pode ser mantido por um período indeterminado de tempo. Todavia, a desvantagem deste método é que a partir do momento que o produto é colocado no mercado, ele pode ser submetido à chamada engenharia reversa e o segredo ser revelado.

Indicação Geográfica consiste na identificação de um produto ou serviço como originário de um local, região ou país, garantindo que reputação, característica e/ou qualidade do produto/serviço possam ser vinculadas essencialmente a esta sua origem particular (INPI, 2010). A legislação em vigor não estabelece prazo de vigência para as Indicações Geográficas, de forma que o período para o uso do direito é o mesmo da existência do produto ou serviço reconhecido.

Patente, a submodalidade mais lembrada quando falamos em Propriedade Intelectual, consiste no direito de exclusividade de exploração temporário de uma invenção ou modelo de utilidade concedido por um governo a pessoas físicas ou jurídicas (INPI, 2010). Em contrapartida, o inventor se obriga a revelar detalhadamente todo o conteúdo técnico da matéria protegida pela patente, incentivando assim novas criações e inovações.

Esta submodalidade pode ser dividida em privilégio de invenção e modelo de utilidade. A primeira é referente a produto ou processo que não exista no estado da técnica, ou seja, a idéia partiu do zero, enquanto modelo de utilidade refere-se a produto ou processo que implique um aperfeiçoamento de algo já existente no estado da técnica, sendo novo apenas em parte de sua estrutura (INPI, 2010). O prazo de vigência de uma patente quando se trata de uma invenção é 20 anos, e o direito de exclusividade de um modelo de utilidade é de 15 anos, contados a partir da data de depósito.

No Brasil, conforme estabelecido no Art. $8^{\circ}$ da Lei da Propriedade Industrial (Lei n ${ }^{\circ}$ 9.279/1996) ${ }^{3}$, são três os requisitos para patenteabilidade: novidade, atividade inventiva e aplicação industrial. O primeiro ocorre quando a invenção não está compreendida no estado da técnica. No caso da atividade inventiva, a mesma consiste na não obviedade a um especialista, ou seja, é a atividade que para um técnico do assunto não decorra de maneira evidente e óbvia. Aplicação industrial consiste na inclusão do produto ou processo na escala de produção industrial (INPI, 2010).

Analisando o sistema de patentes e as legislações referentes ao tema de outros países, verifica-se especificidades e distinções relativas ao contexto, principalmente em relação aos critérios de patenteabilidade para invenções da área biotecnológica. Enquanto no Brasil não se considera invenção nem modelo de utilidade alguns produtos, métodos, materiais e microrganismos, dentre outros, em outros países a proteção é cabível, como é o caso de descoberta, cuja proteção em alguns casos poderá ser concedida nos Estados Unidos.

A título de exemplificação estão apresentados, na Figura 2, os critérios de patenteabilidade para invenções biotecnológicas em diferentes países.

Como em todas as formas de proteção da Propriedade Intelectual, a finalidade de um sistema de patentes é incentivar o desenvolvimento econômico e tecnológico, recompensando a criatividade (OMPI, 2010). Os números de patentes são considerados indicadores relevantes para avaliar a capacidade do país em transformar o conhecimento científico em produtos ou inovações tecnológicas (MCT, 2010).

No ano de 2008 foram depositados no INPI 14.741 pedidos de patentes, sendo que destes, mais de $50 \%$ (7.499) são de inventores não residentes no país. Neste mesmo ano foram expedidas 529 cartas patentes a inventores residentes no Brasil, enquanto que para os não residentes foram expedidas 2.249 cartas patentes. No mesmo ano, o Brasil depositou 499 pedidos de patentes nos Estados Unidos e

\footnotetext{
${ }^{3}$ Art. $8^{\circ}$ - É patenteável a invenção que atenda aos requisitos de novidade, atividade inventiva e aplicação industrial.
} 


\begin{tabular}{|c|c|c|c|c|c|c|c|}
\hline Matéria & Brasil & Austrália & China & $\begin{array}{c}\text { Comunidade } \\
\text { Européia }\end{array}$ & $\begin{array}{l}\text { Estados } \\
\text { Unidos }\end{array}$ & Índia & Japão \\
\hline Descoberta & & & & & & & \\
\hline Material isolado da natureza & & & & & & & \\
\hline Microrganismo isolado & & & & & & & \\
\hline Microrganismo transgênico & & & & & & & \\
\hline Célula humana & & & & & & & \\
\hline Célula animal & & & & & & & \\
\hline Variedade animal & & & & & & & \\
\hline Animal transgênico & & & & & & & \\
\hline $\begin{array}{l}\text { Processo de produção animal } \\
\text { não essencialmente biológico }\end{array}$ & & & & & & & \\
\hline Célula vegetal & & & & & & & \\
\hline Planta Transgênica & & & & & & & \\
\hline Varied ade vegetal & & & & & & & \\
\hline $\begin{array}{l}\text { Processo de produção de } \\
\text { plantas não essencialmente } \\
\text { biológico }\end{array}$ & & & & & & & \\
\hline Método terapêutico & & & & & & & \\
\hline
\end{tabular}

Fonte: Modificado de INPI, 2007.

Figura 2 - Estudo Comparativo dos Critérios de patenteabilidade para invenções biotecnológicas em diferentes países. Em cinza estão as matérias patenteáveis e em branco, as não passíveis de proteção.

obteve a concessão de 131 cartas patentes neste país (MCT, 2010).

De acordo com a gerente de Desenvolvimento Empresarial do Instituto Euvaldo Lodi, Diana Jugmann, "Esses números demonstram que os brasileiros ainda desconhecem a importância econômica e estratégica da Propriedade Intelectual e não sabem se apropriar e nem proteger suas tecnologias” (Revista IEL Interação, 2010). Para que este quadro seja revertido é preciso ações conjuntas dos setores público e privado no sentido de incentivar as criações, inovações e proteções, além do incentivo à mudança de cultura dos brasileiros em relação à proteção dos ativos intangíveis.

\section{O Arcabouço Legal brasileiro}

Conforme ressaltado, a proteção da propriedade intelectual assegura o direito de propriedade e privilégio da exclusividade ao seu titular, ao passo que este divulga à sociedade as informações detalhadas sobre o conhecimento gerado e protegido. Logo, a propriedade intelectual torna-se um mecanismo primordial para o progresso e desenvolvimento e, consequentemente, difusão do conhecimento com o objetivo de proporcionar benefícios à sociedade (Araújo et al., 2008).

O Estado deverá desenvolver uma política para promoção da inovação com vistas ao progresso nacional, em cumprimento ao disposto no artigo 219 da Constituição Federal que disciplina que "O mercado interno integra o patrimônio nacional e será incentivado de modo a viabilizar o desenvolvimento cultural e sócio-econômico, o bem-estar da população e a autonomia tecnológica do País, nos termos de lei federal”.

Visando a efetividade do disposto no artigo acima, foi promulgada a Lei de Inovação, Lei $n^{0} 10.973$, de 02 de dezembro de 2004, que estabelece medidas de inventivo à inovação e à pesquisa científica e tecnológica no ambiente produtivo, com vistas à capacitação e ao alcance da 
autonomia tecnológica e ao desenvolvimento industrial do País, nos termos dos artigos $218^{4}$ e 219 da Constituição.

A Lei de Inovação foi regulamentada pelo Decreto $\mathrm{n}^{0} 5.563$, de 11 de outubro de 2005, e possui como objetivos a constituição de ambiente propício às parcerias estratégicas entre as universidades, institutos tecnológicos e empresas, por meio do disposto em seus artigos $3^{\circ}, 4^{\circ}, 5^{\circ}$ e $9^{\circ}$; estímulo à participação de Instituições de Ciência e Tecnologia no processo de inovação, nos termos dos artigos $6^{\circ}, 7^{\circ}$ e $8^{\circ}$; normas de incentivo ao pesquisadorinventor vinculado à ICT, de acordo com o estabelecido nos artigos $8^{\circ}, 13^{\circ}, 11^{\circ}$ e $15^{\circ}$; e a apropriação dos conhecimentos gerados nas ICTs em favor do setor empresarial, em seu artigo 12 (Barbosa, 2006).

Ainda, a Lei de Inovação dispõe em seus artigos 19 e 20 sobre as formas de incentivo à inovação nas empresas nacionais envolvidas em atividades de pesquisa e desenvolvimento segundo as prioridades da política industrial e tecnológica nacional e sobre a modalidade de exercício do poder de compra do Estado como meio de incentivo à inovação. Por fim, o artigo 28 da referida lei disciplina os incentivos fiscais concedidos a empresas.

Ressalta-se que os estados da federação estão se mobilizando e elaborando as respectivas leis estaduais de incentivo à inovação, dada a necessidade de envolvimento de todas as esferas de governo, federal, estadual e municipal, com essa questão (Lacerda, 2007). Até o presente, foram promulgadas 14 (catorze) Leis Estaduais de Inovação, nos estados de Minas Gerais, São Paulo, Rio de Janeiro, Bahia, Amazonas, Alagoas, Pernambuco, Ceará, Sergipe, Mato Grosso, Goiás, Paraná, Santa Catarina e Rio Grande do Sul.

Ainda, visando o incentivo ao desenvolvimento científico e tecnológico do país, foi promulgada a Lei ${ }^{\circ}$ 11.196, de 21 de novembro de 2005, denominada Lei do Bem, que estabelece os mecanismos para desonerar os investimentos realizados em projetos de inovação, bem como o Decreto $n^{\circ} 5.798$, de 08 de junho de 2006, que regulamenta os incentivos fiscais à inovação.

A Lei do Bem possui como público-alvo todas as empresas que atuam com foco na inovação, com intuito de conceder incentivos fiscais, tais como: deduções de Imposto de Renda e da Contribuição sobre o Lucro Líquido - CSLL de dispêndios efetuados em atividades de P\&D; a redução do Imposto sobre Produtos Industrializados - IPI na compra de máquinas e equipamentos para P\&D; depreciação acelerada desses bens; amortização acelerada de bens intangíveis; redução do Imposto de Renda retido na fonte incidente sobre remessa ao exterior resultantes de Contratos de Transferência de Tecnologia; e isenção do Imposto de Renda retido na fonte nas remessas efetuadas para o exterior destinada ao registro e manutenção de marcas, patentes e cultivares. Entretanto, como parte dos incentivos é destinada ao abatimento de Imposto de Renda e Contribuição Social sobre o Lucro, as empresas que optam pelo chamado Lucro Real, e não pelo Lucro presumido ou Simples Nacional, são as maiores beneficiadas.

\section{A Propriedade Intelectual nas Instituições Científicas e Tecnológicas - ICTs}

Para o avanço científico e tecnológico do país, é imprescindível que as ICTs, no Brasil principais responsáveis pela geração de conhecimento, se normatizem internamente. A elaboração de instrumentos jurídicos como resoluções, atos e portarias é de suma importância para a adequação do ambiente acadêmico aos preceitos normativos referentes à propriedade intelectual.

Nesse contexto, destaca-se o papel dos Núcleos de Inovação Tecnológica - NITs, estabelecido no artigo 16 da Lei de Inovação. Os NITs são responsáveis pela gestão da propriedade intelectual das ICTs e possuem como competências mínimas zelar pela manutenção da política institucional de estímulo à proteção das criações, licenciamento, inovação e outras formas de transferência de tecnologia; avaliar e classificar os resultados decorrentes de atividades e projetos de pesquisa para o atendimento das disposições da Lei; avaliar solicitação de inventor independente para adoção de invenção na forma do art. 22 da referida Lei; opinar pela conveniência e promover a proteção das criações desenvolvidas na ICT; opinar quanto à conveniência de divulgação dessas criações, passíveis de proteção intelectual; acompanhar o processamento dos

\footnotetext{
${ }^{4}$ Art. 218 - O Estado promoverá e incentivará o desenvolvimento científico, a pesquisa e a capacitação tecnológicas.

$\S 1^{\circ}$ - A pesquisa científica básica receberá tratamento prioritário do Estado, tendo em vista o bem público e o progresso das ciências.

$\S 2^{\circ}$ - A pesquisa tecnológica voltar-se-á preponderantemente para a solução dos problemas brasileiros e para o desenvolvimento do sistema produtivo nacional e regional. $\S 3^{\circ}$ - O Estado apoiará a formação de recursos humanos nas áreas de ciência, pesquisa e tecnologia, e concederá aos que delas se ocupem meios e condições especiais de trabalho.

$\S 4^{\circ}$ - A lei apoiará e estimulará as empresas que invistam em pesquisa, criação de tecnologia adequada ao País, formação e aperfeiçoamento de seus recursos humanos e que pratiquem sistemas de remuneração que assegurem ao empregado, desvinculada do salário, participação nos ganhos econômicos resultantes da produtividade de seu trabalho.

$\S 5^{\circ}$ - É facultado aos Estados e ao Distrito Federal vincular parcela de sua receita orçamentária a entidades públicas de fomento ao ensino e à pesquisa científica e tecnológica.
} 
pedidos e a manutenção dos títulos de propriedade intelectual da ICT.

Somente por meio da atuação dos NITs e da consolidação de uma política de propriedade intelectual na ICT que será alcançada uma efetiva proteção do conhecimento gerado em seu âmbito. Para tanto, destaca-se a importância da assinatura do Termo de Sigilo, da adoção do questionário de invenção e da celebração do Contrato de Autores e Inventores pelos membros da equipe de pesquisa, mecanismos fundamentais para assegurar a tutela dos direitos intelectuais.

Tendo em vista que durante o desenvolvimento das pesquisas ocorre um manuseio de informações sigilosas e, concomitantemente, considerando o envolvimento e acesso a tais informações por diversos professores/ pesquisadores, técnicos administrativos e estudantes, principalmente no âmbito acadêmico em que, considerando como a missão principal das universidades, a formação de profissionais com alto nível de qualificação, faz-se necessário o livre trânsito de informações, tornando-se imprescindível a assinatura de Termo de Sigilo nos laboratórios (Araújo et al., 2008).

O sigilo de tais informações deve ser preservado, haja vista que a divulgação indevida poderá inviabilizar o pedido de proteção juntos aos órgãos competentes. Ainda, sua assinatura pelos inventores da inovação visa assegurar seus direitos diante da atuação desleal de algumas empresas que atuam no seguimento mercadológico em que a propriedade intelectual está relacionada, haja vista que algumas empresas visam ter acesso ao conhecimento gerado, sem que efetuem investimentos pecuniários no desenvolvimento da pesquisa. Logo, o Termo de Sigilo é o instrumento jurídico hábil a assegurar a manutenção do sigilo e conscientizar os envolvidos na pesquisa sobre a importância e necessidade do sigilo das informações.

O questionário de invenção permite ao NIT conhecer detalhadamente o desenvolvimento da pesquisa, bem como os envolvidos na geração da propriedade intelectual. Por meio do questionário, é possível identificar se a pesquisa foi desenvolvida em parceria com o setor privado e se houve financiamento de uma agência de fomento para seu desenvolvimento. Nesses casos, a titularidade deverá ser compartilhada entre a ICT e esses agentes. Em relação à identificação dos envolvidos na pesquisa, o questionário permite identificar quais professores/pesquisadores, técnicos administrativos e estudantes que contribuíram intelectualmente para a geração da inovação.

Após a identificação desses inventores, é imprescindível que seja assinado o Contrato de Autores e Inventores para que seus direitos fiquem resguardados na proporção de sua contribuição intelectual e para evitar que, caso haja a transferência de tecnologia, haja questionamentos sobre o grau de participação no recebimento dos recursos pecuniários advindos por cada envolvido, de forma que sua assinatura deverá ocorrer anteriormente ao requerimento da proteção junto aos órgãos competentes.

Cabe salientar que, além da retribuição pecuniária devida ao inventor, prevista no artigo 13 da Lei de Inovação, a ICT poderá adotar uma política de desempenho visando valorar a inovação gerada pelos inventores como um dos critérios na realização de concurso para a classe de professor titular da instituição, bem como nas progressões horizontais e verticais do plano de carreira.

Por fim, ressaltamos que cabe às ICTs, por meio dos NITs, estimularem a cultura da proteção da propriedade intelectual gerada na Instituição, podendo as mesmas integrarem e atuarem em rede, aprimorando-se e avançando na gestão da propriedade intelectual.

\section{A tendência atual brasileira no contexto da Propriedade Intelectual}

Como mencionado anteriormente, para o alcance do objetivo de uma nação de promover o progresso científico e tecnológico e, consequentemente, a inovação, associado ao desenvolvimento econômico e social do país, é necessário ações conjuntas de vários setores, como as ICTs, as empresas, o SEBRAE, as incubadoras de empresas, os parques tecnológicos, as agências de fomento, bem como o governo de forma geral, por meio de legislações, políticas de incentivo e financiamento à pesquisa e desenvolvimento, propriedade intelectual e, por conseqüente, à inovação.

O Brasil, principalmente nos últimos 13 anos, vem implementando políticas visando fomentar o cenário da proteção intelectual e da inovação no país. Ao longo desses anos, o governo aprovou a Lei de Inovação, a qual deu origem às Leis Estaduais de Inovação, a Lei do Bem e a Lei de Incentivos Fiscais, Lei ${ }^{\circ} 11.196$, de 21 de novembro de 2005; lançou, em 2004, a Política Industrial, Tecnológica e de Comércio Exterior, com objetivo de avançar economicamente e de promover o desenvolvimento de tecnologias com potencial de competição no mercado internacional; estabeleceu, em 2007, o Plano Ação de Ciência, Tecnologia e Inovação, visando tornar mais decisivo o papel da ciência, tecnologia e inovação no desenvolvimento sustentável do país; em 2008, implementou o Programa de Desenvolvimento Produtivo, cujo objetivo é dar continuidade ao crescimento do país em diversas áreas, com ênfase na inovação, na competitividade, no apoio ao 
empreendedorismo e no aumento das exportações, entre outras políticas.

Nesse contexto, insere-se uma importante tendência de trabalho em rede, com a construção de redes que participam e contribuem ativamente no processo de alavancagem da pesquisa, da proteção intelectual, inovação e, concomitantemente, do desenvolvimento científico e tecnológico do país.

No cenário atual, a construção de redes representa uma estratégia fundamental de disseminação e consolidação da cultura da propriedade intelectual, de transferência de tecnologia e de inovação nos estados e no país, permitindo a troca de informações, experiências, bem como interações entre as instituições que as compõem, visando ao aprimoramento de suas ações no âmbito da proteção e transferência do conhecimento, bem como a consolidação da atuação de seus núcleos de inovação tecnológica. Além disso, a construção de redes viabiliza e facilita a capacitação dos profissionais, formando multiplicadores de conhecimento no tema da propriedade intelectual, transferência de tecnologia e da inovação.

No Brasil, pode-se citar a criação das seguintes redes relacionadas à disseminação da proteção, transferência do conhecimento e da inovação científica e tecnológica: Rede de Tecnologia do Rio de Janeiro - REDETEC, Rede de Propriedade Intelectual, Cooperação, Negociação e Comercialização de Tecnologia-REPICT, Rede Paranaense de Gestão da Propriedade Intelectual, Rede Norte de Propriedade Intelectual, Biodiversidade e Conhecimento Tradicional, Rede NIT-NE - Rede Nordeste, Rede de Propriedade Intelectual de Mato Grosso do Sul, Rede de Propriedade Intelectual e Transferência de Tecnologia da Bahia-REPITTec, Rede de Propriedade Intelectual para o Desenvolvimento Tecnológico e Inovação de Alagoas e a Rede Mineira de Propriedade Intelectual - RMPI. Além disso, encontra-se em fase de criação a Rede do Estado do Rio Grande do Sul.

Na criação de redes, bem como na manutenção de suas atividades, surge um ator de fundamental importância nesse processo: as agências de fomento. Esta questão, ou seja, a interação entre redes que auxiliam na disseminação da propriedade intelectual e da inovação e as agências de fomento, pode ser visualizada no estado de Minas Gerais. Neste estado, a RMPI faz parte do grupo de redes de pesquisas credenciadas e fomentadas pela agência de fomento Fundação de Amparo à Pesquisa do Estado de Minas Gerais - FAPEMIG, por meio do Programa de Apoio a Redes. $\mathrm{O}$ apoio concedido pela FAPEMIG à Rede Mineira, desde a sua criação, em 2003, mostrou-se fundamental para a consolidação do trabalho em rede no estado, contribuindo para o desempenho das atividades desenvolvidas pela RMPI.

Diante da importância da relação entre as redes de propriedade intelectual, transferência de tecnologia e inovação e as agências de fomento, ressalta-se que, em 2008, a manutenção das atividades da RMPI passou a ser oficialmente parte integrante da política de estímulo à proteção de propriedade intelectual da FAPEMIG, sendo publicada a deliberação nº 34/2008 da referida agência de fomento que, entre outros pontos, define no Art. 10: "Estabelecer que a FAPEMIG poderá auxiliar na manutenção da Rede Mineira de Propriedade Intelectual e participar da mesma como membro".

\section{Considerações Finais}

Em suma, à medida que a propriedade intelectual se destaca como um fator estratégico para a inovação científica e tecnológica e como instrumento imprescindível na competitividade e autonomia tecnológica de um país, o que se verifica no Brasil é a convergência dos setores público e empresarial, os quais buscam se interagirem com o propósito de contribuir para o desenvolvimento científico, tecnológico e social do país, visto que desta forma se estabelece um processo contínuo, com ações coordenadas e conjuntas de toda a sociedade.

\section{Referências}

ADENACON - Marcas e Patentes. Disponível em: <http:// www.adenacon.com.br/servicos/registro-topografia-de-circuitointegrado> Acesso em: 22/4/2010.

ARAÚJO, E.F.; QUEIROGA, E.S.; GROENNER, L.C. Política de Propriedade Intelectual e Inovação: a gestão nas universidades, o contrato de autores e inventores, termo de sigilo e a transferência de tecnologia. In: ADOLFO, L.G.S.; MORAES, R. (Orgs.). Propriedade Intelectual em perspectiva. Rio de Janeiro: Lúmen Juris, 2008, p.91-100.

ARAÚJO, N.L. Revista Jurídica Consulex/Dialex, Ano XXV, Edição $\mathrm{n}^{\circ}$ 73, Brasília, 17 de abril de 2007.

BARBOSA, D.B. [2007]. Breves comentários à Lei n 11.484, de 31 de maio de 2007, que introduz proteção exclusiva à Topografia de Circuitos Integrados.

BARBOSA, D.B. Do segredo industrial. Disponível em: < http:/ /denisbarbosa.addr.com/92.doc > Acesso em: 23/4/2010.

BARBOSA, D.B. Direito da Inovação (Comentários Lei n. 10.793/ 2004, Lei Federal de Inovação). Rio de Janeiro: Lúmen Júris, 2006.

BRASIL. Decreto $n^{\circ} 5.563$, de 11 de outubro de 2005. Regulamenta a Lei $n^{\circ} 10.973$, de 2 de dezembro de 2004, que dispõe sobre incentivos à inovação e à pesquisa científica e tecnológica no ambiente produtivo, e dá outras providências. Diário Oficial [da] República Federativa do Brasil, Brasília, DF, 13 out. 2005. Disponível em: <http://www.planalto.gov.br/ccivil_03/ _ato2004-2006/2005/Decreto/D5563.htm.> Acesso em: 26/4/ 2010 . 
BRASIL. Lei $n^{\circ} 9.279$ de 14 de maio de 1996. Regula direitos e obrigações relativos à propriedade industrial. Diário Oficial [da] República Federativa do Brasil, Brasília, DF, 15 mai. 1996. Disponível em: <http://www2.camara.gov.br/internet/ legislacao/legin.htmlvisualizarNorma.html?ideNorma $=374644 \&$ PalavrasDestaque $=>$. Acesso em: 23/4/2010.

BRASIL. Lei $n^{\circ}$ 9.456, de 25 de abril de 1997. Institui a Lei de Proteção de Cultivares e dá outras providências. Diário Oficial [da] República Federativa do Brasil, Brasília, DF, 28 abr. 1997. Disponível em: <http://www2.camara.gov.br/internet/ legislacao/legin.html/alizarNorma.html?ideNorma $=349440 \&$ Palavras Destaque=>. Acesso em: 23/4/2010.

BRASIL. Lei $n^{\circ}$ 9.609, de 19 de fevereiro de 1998. Dispõe sobre a proteção da propriedade intelectual de programa de computador, sua comercialização no País, e dá outras providências. Diário Oficial [da] República Federativa do Brasil, Brasília, DF, 20 fev. 1998. Disponível em: < http://www2.camara.gov.br/ internet/legislacao/legin.html/visualizarNorma.html?ide Norma $=364738 \&$ PalavrasDestaque $=>$ Acesso em: 23/4/2010.

BRASIL. Lei $n^{\circ}$ 9.610, de 19 de fevereiro de 1998. Altera, atualiza e consolida a legislação sobre direitos autorais e dá outras providências. Diário Oficial [da] República Federativa do Brasil, Brasília, DF, 20 fev. 1998. Disponível em: < http:// www2.camara.gov.br/internet/legislacao/legin.html/ visualizarNorma.html ideNorma $=365399 \&$ PalavrasDestaque $=>$ . Acesso em: 23/4/2010.

BRASIL. Lei $n^{\circ} 10.973$, de 02 de dezembro de 2004. Dispõe sobre incentivos à inovação e à pesquisa científica e tecnológica no ambiente produtivo e dá outras providências. Diário Oficial [da] República Federativa do Brasil, Brasília, DF, 03 dez. 2004. Disponível em: <http:// www.planalto.gov.br/ccivil_03/_ato2004-2006/2004/Lei/ L10.973.htm >. Acesso em: 26/4/2010.

BRASIL. Lei ${ }^{\circ}$ 11.196, de 21 de novembro de 2005. Diário Oficial [da] República Federativa do Brasil, Brasília, DF, 22 nov. 2005. Disponível em: < http://www.planalto.gov.br/ ccivil_03/_Ato2004-2006/2005/LEI/L11196.htm> Acesso em: 26/4/2010.

BRASIL. Lei ${ }^{\circ} 11.484$, de 31 de maio de 2007. Diário Oficial [da] República Federativa do Brasil, Brasília, DF, 31 mai. 2007. Disponível em: < http://www.inpi.gov.br/menu-esquerdo/ topografia-de-circuitos/legislacao/index.htm/impressao_view > Acesso em: 23/4/2010.
DI BLASI, G. A propriedade industrial: os sistemas de marcas, patentes e desenhos industriais analisados a partir da Lei $\mathrm{n}^{\circ}$ 9.279, de 14 de maio de 1996. Rio de Janeiro: Forense, 2005.

FUNDAÇÃO DE AMPARO À PESQUISA DO ESTADO DE MINAS GERAIS. Disponível em: http://www.fapemig.br/. Acesso em: 20/4/2010

INOVA - UNICAMP - Material de treinamento - PI Básico. Disponível em: http://www.inova.unicamp.br/paginas/inovanit/ loginUsuario.php Acesso em: 22/4/2010.

INSTITUTO EUVALDO LODI. Inovação é qualidade de vida. Revista IEL Interação. Ano 18, nº 209, p.8-11, 2010.

INSTITUTO EUVALDO LODI. Ferramenta para a inovação. Revista IEL Interação. Ano 18, nº 209, p.12-19, 2010.

INSTITUTO EUVALDO LODI. Conhecimento e competitividade. Revista IEL Interação. Ano 18, n 209, p.38, 2010.

INSTITUTO NACIONAL DE PROPRIEDADE INTELECTUAL - INPI. Disponível em: <http://www.inpi.gov.br> Acesso em: 20/4/2010.

JUGMANN, D. Ferramenta para a inovação. Interação. Mar/Abr/Maio 2010. p.12-19.

MARCO REGULATÓRIO DE APOIO À INOVAÇÃO NO BRASIL. Disponível em: <http://www.propintelectual.com.br/site/ index.php?option=com_content\&view=article\&id=22\&Itemid=29>. Acesso em: 26/4/2010.

MINISTÉRIO DA AGRICULTURA PECUÁRIA E ABASTECIMENTO - MAPA. Serviço Nacional de Proteção de Cultivares. Informações aos Usuários do SNPC. Disponível em: < http:// www.agricultura.gov.br/pls/portal/docs/PAGE/MAPA/SERVICOS/ CULTIVARES/PROTECAO/INFORMACOES_USUARIOS_ PROTECAO/INFORMA \%C 7\%D5E S\%20A OS\%20USU \%C1RIOS\%20DO\%20SNPC_OUTUBRO \%20DE\%202008_0_0. PDF > Acesso em: 23/4/2010.

MINISTÉRIO DA CIÊNCIA E TECNOLOGIA - MCT. Indicadores Nacionais de Ciência e Tecnologia. Disponível em: <http:/ /www.mct.gov.br/index.php/content/view/740.html?execview=> Acesso em: 22/4/2010.

ORGANIZAÇÃO MUNDIAL DE PROPRIEDADE INTELECTUAL - OMPI. Disponível em: < http://www.wipo.int/academy/en/ courses/distance_learning/catalog/pt/c_index.html >. Acesso em: 23/4/2010.

REDE MINEIRA DE PROPRIEDADE INTELECTUAL - RMPI. Disponível em: <http://www.redemineirapi.com> Acesso em: 20/4/2010. 